\title{
'Shadowing' and its place in preparing students for practice learning
}

\author{
Jonathan Parker ${ }^{1}$, Mel Hughes ${ }^{2} \&$ Lynne Rutter $^{3}$
}

Summary: As part of the new social work degree in England all students must undergo a period of assessed preparation for practice learning which includes the opportunity to shadow an experienced social worker. This requirement has been implemented in different ways across social work programmes in England and providers have raised concerns about the assessment of students' fitness to undertake practice learning. This article explores the background to and potential of 'shadowing' as observational and preparatory leaning and surveys some of the differential practice amongst English social work programme providers. Following this, the article describes a small-scale research study in which the confidence (self-efficacy beliefs) of students were monitored before and after undertaking shadowing experiences and qualitative reports concerning the experiences were collected and reviewed. The study recommends the development of a rigorous approach to shadowing, that is assessed, made integral to social work programmes and is adequately resourced.

Keywords:shadowing placements; preparations for practice; self-efficacy

1. Professor of Social Work at Bournemouth University

2. Lecturer in Social Work at Bournemouth University

3. Lecturer in Student Support

Address for Correspondence: Professor Jonathan Parker, Bournemouth University, School of Health and Social Care, 4th Floor, Royal London House, Bournemouth, BH1 3LT, UK. parkerj@bournemouth.ac.uk

49 Journal of Practice Teaching \& Learning 7(3) 2006-07, pp.49-69. DOI: 10.1921/19643. ( $w \mathcal{E} b$ 


\section{Introduction}

Under section 67 (1) of the Care Standards Act 2000 the Secretary of State is accorded the function of determining what training is required by social care workers. The specific requirements for social workers in England, as a distinct profession, are delineated in the Department of Health (2002) document Requirements for the Training of Social Workers. Section 63 of the Act gave the General Social Care Council (GSCC) - the professional regulatory body for social work in England - the responsibility for approval of social work courses, which must adhere to the requirements specified by the Department of Health. It was left, however, to individual universities to decide how they were to meet these requirements, alongside a host of other standards such as the National Occupational Standards for social workers (TOPSS, 2002) and the subject benchmarks (QAA, 2000) for undergraduate degree qualifications.

The Department of Health (2002) outlines two sets of requirements, those that relate to student admission and those that concern teaching, learning and assessment. Requirement $\mathrm{K}$ of the latter set states that providers (of programmes; namely, universities) must:

Ensure that all students undergo assessed preparation for direct practice to ensure their safety to undertake practice learning in a service delivery setting. This preparation must include the opportunity to develop a greater understanding of the experience of service users and the opportunity to shadow an experienced social worker. (Department of Health, 2002, p.3)

There are some difficulties with requirement K. Firstly, the rationale behind 'shadowing' is to form part of the assessed preparation for practice that aims to ensure students' safety to undertake practice learning within 'service delivery settings'. This may imply that learning for practice does not only take place in practice agencies, which may have implications for the previous requirement J, 'that all social work students spend at least 200 days gaining required experience in practice settings' (Department of Health, 2002, p.3, bold in original). A liberal interpretation may suggest practice learning is possible within a 'safe' environment such as a skills laboratory. A second, more complex, problem relates to the assurance that a student is safe to undertake practice learning and the assumption that college-based academics are

50 Journal of Practice Teaching \& Learning 7(3) 2006-07, pp.49-69. DOI: 10.1921/19643. ( wEb 
in a position to judge that safety. The evaluation of students' preparation for agency-based learning may be achieved by the assessment of a range of university-based modules concerned with skills development and understanding the experiences of service users. This type of evaluation remains clearly within the competence of academics. It is more difficult to assess 'safety' to undertake practice learning. A clear definition of the term 'safety' is required but not provided. The requirement also begs many questions as to what might happen or what sanctions may apply should a student be judged 'unsafe' when undertaking practice learning. No working guidance is provided; perhaps suggesting the requirement has been developed without full regard to its implications. The lack of guidance may suggest a risk-averse sense of accountability that focuses responsibility on the universities. The assessment is undertaken at a particular moment in time and cannot be construed as a guarantee of durable safety but only a potential indicator at best. As experience develops, perhaps, programmes will have a firmer basis on which to plan and execute these requirements.

Whilst there are problems with the requirement for shadowing there are also potential benefits to be gained from the experience. The shadowing experience is one aspect of practice preparation only. It is important to determine what aims and outcomes are desired from the experience and how these might be achieved by the processes in which the students engage. If we are to determine the benefits we need to be able to measure these in meaningful ways. In order to build our evidence base, with a view to enhancing and improving practice, we need also to examine how the experience prepares people for practice and what benefits may be accrued from it whilst ensuring the experience is constructed in the best possible manner to achieve this.

This paper explores the shadowing placement and its purported intention to prepare students for practice learning across a sample of 14 social work programmes in England. The development of selfefficacy beliefs in students who have undertaken shadowing and their perceptions once in practice learning are then examined with a view to enhancing and improving the shadowing experience as a means of preparing students for practice learning.

51 Journal of Practice Teaching \& Learning 7(3) 2006-07, pp.49-69. DOI: 10.1921/19643. @ wE-b 


\section{Preparation for practice learning}

If practice is central to the social work degree (Department of Health 2002, Parker, 2006; 2007), then it must be the case that preparation for learning in practice is also important. The assessment of this preparation is a requirement of social work programmes, and, indeed, the GSCC specifically consider evidence of the adequacy of the assessment in the annual monitoring of external examiner reports (GSCC, 2003). How students are prepared for practice learning, however, remains the responsibility of individual programmes.

Maidment's (2003) research in Australia provides important evidence concerning what students need to know to be prepared for practice. She questions the adequacy of traditional preparation that seems to have focused on the skills base for engaging with and maintaining relationships with service users. Although such skills are crucial to good practice, she believes they do not adequately address the intra-psychic anxieties and concerns of students in coping with the pressures and stresses of social work. Maidment suggests, therefore, that social work programmes need to teach students how to survive and negotiate in workplace cultures and not only the traditional interview and assessment skills. Gelman (2004) considers it possible that prior voluntary experience may help alleviate some of the anxieties associated with field education, a suggestion that may imply possible preparatory benefits can be drawn also from the shadowing experience.

There has been other concern expressed with the adequacy of student preparation for practice learning. In Canada, Barlow and Coleman (2003) and, in Australia, Plath (2003) considered these issues. As the devolution of awarding powers took hold within the UK, Douglas and Byrne (2005) reported on the differing views of preparation for practice learning expressed by practice teachers and students in Northern Ireland. In the main, students did not believe their preparation was adequate, whilst tutors considered it to be 'fit for purpose'. Because of the agreed importance of preparation for practice learning, this research led to standardisation and improvement in student preparation across Northern Ireland.

In England, Furness and Gilligan's (2004) discussion of the concept of 'preparedness to practise' explored emergent issues such as the need for definition and measurement of 'good enough' practice, the determination of students' 'suitability' for social work and the role of

2 Journal of Practice Teaching \& Learning 7(3) 2006-07, pp.49-69. DOI: 10.1921/19643. @ wEb 
'Shadowing' and its place in preparing students for practice learning

the practice educator. Explanation and discussion of these concepts with students to make them more explicit (especially for assessment purposes) is advocated so that students can take a more active and reflective role in this preparation and establish their learning needs. Furness and Gilligan believe using such tools as progress development files - a tool designed to chart and identify student learning and future needs in English universities - may assist this process. However, the provision of adequate funding for such preparation for practice learning opportunities was considered to be a key determinant for further improvement.

Later work by Walton (2005) has echoed some of these findings. Examining the essential elements of good preparation through the literature reiterated the necessity to clarify such concepts as 'fitness', 'readiness', 'preparedness'; as well as the role of degree courses as 'gatekeepers' or assessors of student safety. Walton also raised interesting points regarding the role of anxiety, timing and content of such preparation and the assessment methods employed to test it. Walton's study considered an evaluation of preparation programmes undertaken at Sheffield and Sheffield Hallam Universities for qualifying students undertaking their first practice learning opportunity, focusing on practice assessors' perspectives. Although some particular aspects were valued and appeared to enhance the practice learning opportunity (in particular the two-day shadowing experience and communication skills course) there was concern expressed by the practice assessors about students' ability to relate what they had learnt at university to actual practice. Students tended to view and separate all but the most practical elements as academic learning, and not share information on their preparation with their practice assessors. Recommendations were therefore made for more explicit linkages via an understanding of the framework in which social work operates, including such matters as task and role, context, and service users and carers' perspectives. Most importantly, it was noted that all aspects of preparation should be discussed explicitly with students, used as the basis for establishing individual learning needs, and shared with their practice assessors.

53 Journal of Practice Teaching \& Learning 7(3) 2006-07, pp.49-69. DOI: 10.1921/19643. (C) wEb 


\section{Shadowing and observation}

Shadowing, as the practice of accompanying others to see and learn from their practice (Gould, 2000, p.588), is a well-used method of promoting learning on placement. Learning by modelling takes the activity one step further so that, as well as observing an experienced practitioner demonstrate a skill, a student or novice will seek to imitate the practitioner's behaviour at a later time. As such, modelling can be used as a method for learning very complex behaviours and is one of the more holistic ways to ensure readiness for practice (Shardlow \& Doel, 1996).

Social work consists of a range of complex and implicit skills, knowledge and values that are not always easy to define precisely (Horner, 2006). By shadowing and observing an experienced social work practitioner, some of these implicit abilities and processes become more visible and so the content of practice becomes more open and accessible (Shardlow \& Doel, 1996), or at least open to reflection. Observing others in this way can therefore provide much raw material from which a novice practitioner can develop their own approach to practice.

However, it appears that observational learning has its own set of dynamics and the observer's entry into a situation will influence what occurs there, with the participants possibly taking on artificial roles believed by them to be appropriate (Weade and Evertson, 1991, p.41). Shardlow and Doel (1996) discuss other inherent problems, for example the reluctance of practice teachers to advocate the 'one-way is best' of doing things, the subjective nature of choosing models to focus on, and issues of power differentials between the observer and observed. These problems highlight the need for clear planning to limit their potential to inhibit learning. This might be achieved, for example, by developing a pre-agreed focus on a theme, and providing directed reflection and feedback. The transfer of learning to other areas of practice can be supported by encouraging reflection before and after the event via writing or feedback sessions, and connections made with the literature, policy and legislation (Moon 1999).

As Weade and Evertson (1991) note observation is a multifaceted phenomenon. It is a tacit feature of ordinary everyday action but also has the potential to become a more deliberate act and embody a more conscious and formal role in student learning. The latter situation requires a clear direction and a focus in order to be most effective. With

54 Journal of Practice Teaching E Learning 7(3) 2006-07, pp.49-69. DOI: 10.1921/19643. @ wE-b 
'Shadowing' and its place in preparing students for practice learning

a defined and negotiated learning purpose students may observe wider practice processes than just the behaviour of the observed practitioner; for instance a home visit encompasses a wider set of features and processes than an individual's interpersonal skills. This allows the student shadowing the social worker the opportunity to compare, contrast and collate impressions from the whole experience itself. Macaulay (2000) suggests that shadowing experiences align with approaches advocated for the transfer of learning for professional education as they enable students to engage with a situation and to experience its complexity at first hand. Students can then reflect on and extract the principles of a situation for themselves, which facilitates deeper understanding than a more passive taught approach.

Le Riche (2006) has taken the notion of preparation and support for the shadowing experience further and designed an observational curriculum using a theoretical and practical context for the BA (Hons) Social Work. The aim is to improve a student's 'readiness for placement'. Emphasis is placed on the importance of observational learning, which is supported via the negotiation of realistic learning outcomes, a staged learning process, completion of a reflective journal, and an assessed workbook. Shadowing can be an uncomfortable experience because of perceived power imbalances between student and practitioner or between student, practitioner and service user. On placement it has been seen that some students find it difficult to fully appreciate the mutual benefit of open discussion about practice (Rickard, 2002). Students can feel unworthy and have a lack of confidence in their own ability or express anxieties about being assessed. The complexities of power relations are therefore made more explicit in the curriculum described by Le Riche, and ethics and values explored initially within a 'safe' university environment prior to placement.

Initial evaluations from Le Riche's work (2006) have shown that observation in a shadowing experience provides an important introduction to key aspects of professional learning, such as antioppressive practice and communication skills. Other learning goals include the development of reflective capacity, an increased level of critical awareness, exploration of values and preconceptions; all of which aid the process of developing a professional identity. Shadowing thus allows students to participate in a social work community and begin to construct identities in relation to it. In this respect learning becomes more than the acquisition of certain forms of knowledge and is 
placed within social relationships and situations of co-participation, as advocated by Lave \& Wenger's (1991) communities of practice. Another potential outcome of this social learning is the development of a learning culture within the organisation (Gould, 2000), in which observation and shadowing becomes an integral part of its professional activity.

The concept of self-efficacy presents an important means of exploring and developing competence and effectiveness (Bandura, 1977, 1986), and may help in planning and evaluating student experiences on shadowing placements. The theoretical basis for self-efficacy stems from social learning theory.

Self-efficacy suggests that whilst a person may know what actions need to be undertaken in order to execute a particular task (outcome expectations) successfully, there needs also to be an element of belief or confidence in the ability to perform those actions in order to achieve effective completion (efficacy expectations) (Bandura, 1986). It is, therefore, more than simply a perception of competence (Holden et al., 2002). One of the key ways in which self-efficacy beliefs are formed is by the modelling of the behaviour of others. An opportunity for modelling of good practice and dealing with the anxieties and events of the day may begin during the shadowing experience. However, our self-efficacy beliefs also depend on our life experiences and interpretation of these, receiving verbal encouragement and constructive criticism, and from the resolution of anxiety and stress in certain situations (Pajares, 2002). These sources of self-efficacy beliefs are useful to bear in mind when developing shadowing experiences or indeed offering them.

By measuring self-efficacy beliefs and their development it may be possible to provide some evidence indicating the value, positive or not, of the shadowing experience. This is because, as Parker (2006, p.1023) points out:

a strong belief in the ability to do something tends to be associated with an approach that sees challenges as things to be mastered rather than threats to be avoided and this, in turn, increases a commitment to goal achievement and persistence in the face of failure (Bandura, 1994). This suggests that a strong belief in the ability to perform social work tasks will lead to persistence and commitment and an active focus on the achievement of desired goals. The corollary of this is that students who have low selfefficacy may not perform well during practice learning and will need a greater level of support to succeed, or may counsel themselves away from

56 Journal of Practice Teaching \& Learning 7(3) 2006-07, pp.49-69. DOI: 10.1921/19643. @ wEb 
'Shadowing' and its place in preparing students for practice learning

a career in social work, choosing a different option more suited to their needs. If students' self-efficacy can be enhanced during shadowing then it may be suggested that this prepares them better for practice learning, and for learning at a higher level.

The theory provides a model for understanding differential performance by social work students dealing with shadowing opportunities and experiences. It offers social work educators and shadowing opportunity providers opportunities to identify ways of assisting the learning process by building on constructive experiences, which may be extremely important in planning effective means of preparing students for practice (see Parker, 2005; 2006). By collecting self-efficacy data it may be possible to match shadowing experiences, social work supervisors and students to maximise their learning from observation. This may be achieved by considering individual need for encouragement and the appropriate reduction of stress and anxiety as well as taking into account prior experiences in work and throughout life.

\section{Methodology}

The study was carried out using a three-stage approach. The first stage collected background contextual information relating to shadowing practices across a sample of social work programmes in England in order to provide a baseline of practice. Social work programme contacts in England were invited via email, to send information about the ways in which shadowing was implemented and copies of the policy, procedures and any forms used. Assurances of anonymity were provided for respondents.

As noted earlier, the self-efficacy model suggests that student confidence in being able to complete specific tasks is associated with success and perseverance. Testing changes in confidence by completing a pre-shadowing and post-shadowing questionnaire, therefore, may add to our knowledge of the effectiveness or otherwise of the shadowing experience. In the second-stage of the research, a pre- and post-test questionnaire asking students to rate their confidence in completing specific social work tasks was administered to students prior to and after

57 Journal of Practice Teaching \& Learning 7(3) 2006-07, pp.49-69. DOI: 10.1921/19643. (C) wEb 
their shadowing experiences. The questionnaire reflected an amended version of a reliable self-efficacy questionnaire used previously in practice learning (Parker, 2005; 2006). A retrospective test was included alongside the second completion of the questionnaire (at post-test) to gauge how students perceived they had developed in confidence after the experience. This retrospective completion allowed a check that students were not scoring themselves lower at this point because of an increased awareness of the complexities of practice gained from the shadowing experience. (A second group completed the self-efficacy questionnaire at a later date to replicate the test and add confidence to the findings.) Prior to the administration of the questionnaire a focus group was held to ascertain qualitative feedback on the fears and expectations involved in the shadowing process. The findings from both parts of the survey were compared and contrasted and data were analysed using a mixed method approach of statistical techniques and analysis of themes and categories within the qualitative data.

Subsequently, when this cohort of students were undertaking practice learning, a third-stage was undertaken in which an open-ended questionnaire was circulated to ascertain the perceived benefits and limitations of the shadowing experience as a means of preparing them for practice learning. The data were analysed qualitatively to identify core themes and issues arising.

At all stages throughout the study, participants were assured that any responses would remain anonymous, that they could withdraw consent to be involved at any time and that data would be used to enhance the shadowing experience and for dissemination to others including publication. 
'Shadowing' and its place in preparing students for practice learning

\section{Findings}

We received 14 responses to our request for information from universities on shadowing placements. In our review of shadowing methods and criteria across programmes in England we considered the following areas:

- length of the experience offered by responding programmes,

- how these were arranged,

- in what ways the experiences were assessed,

- what preparation students were given, and

- what forms or guidance were provided

Other qualitative comments were also considered.

Despite being a requirement of the degree (Department of Health, 2002), not all programmes had formal shadowing arrangements in place. For those who did, the length of shadowing ranged from one day to 10 days (one University reported 14 days but four of these could be spent in the university). The breakdown is shown in the frequency table 1 and indicates clustering towards the extremes of the range.

Universities were responsible for the arrangement and allocation of shadowing experiences in the majority of cases although some universities asked students to undertake shadowing prior to beginning the programme and some allocated shadowing placements according to the extent of a student's prior experience in social care work. One programme linked shadowing with the first practice learning opportunity and integrated it with the 200 practice learning days, which seems incongruent with the Department of Health (2002) requirements.

Shadowing experiences were assessed in a variety of ways from perfunctory level statements of 'fitness' or tick box summaries of the experience to the production of experiential and reflective diary entries, feedback sheets or essays as part of assessed and accredited modules. Similarly, students were prepared for the experience in different ways. Some were given short briefing notes; others undertook specific skills and knowledge training on modules or attended bespoke seminars relating to the shadowing opportunity. The level of assessment and preparation activities matched the place the shadowing opportunity had within programmes. Where shadowing formed part of an academic module, guidance notes and information were comprehensive and

59 Journal of Practice Teaching \& Learning 7(3) 2006-07, pp.49-69. DOI: 10.1921/19643. (C) wEb 
Table 1

Days allocated to shadowing opportunities

\begin{tabular}{cccc}
\hline $\begin{array}{c}\text { Days } \\
\text { allocated }\end{array}$ & $f$ & $\begin{array}{c}\% \\
\text { (to nearest integer) }\end{array}$ & $\begin{array}{c}\% \\
\text { cumulative }\end{array}$ \\
\hline 0 & 1 & 7 & 7 \\
1 & 4 & 29 & 36 \\
2 & 3 & 21 & 57 \\
3 & 1 & 7 & 64 \\
4 & 0 & 0 & $(64)$ \\
5 & 1 & 7 & 71 \\
6 & 0 & 0 & $(71)$ \\
7 & 0 & 0 & $(71)$ \\
8 & 0 & 0 & $(71)$ \\
9 & 0 & 0 & $(71)$ \\
10 & 4 & 29 & 100 \\
\hline
\end{tabular}

contained with module guides; whereas if the experience operated as a stand-alone activity guidance tended to be fairly brief.

In providing further information, respondents were generally agreed that the shadowing placement could be a useful experience; however, its relevance was questioned by programmes when the time offered was short and other pressures prevented its expansion. The experience was criticised by some programme providers as shown in the following quotation:

... social workers are spending more and more time behind computers and at their desks. A few students last year didn't even leave the office! I'm not sure how useful this is really and what it actually achieves. As part of the 'safe to undertake practice experience' I'm not sure what it shows. Our students do spend time with service users and carers in college before they go on practice and I am thinking that this may be more valuable... Having said that we have had valuable feedback from social workers around discussions they have had with students ... that in one case raised serious cause for concern, so it does have a place.

A further challenge to the intention to test safety or provide experience by shadowing experienced and qualified social workers was provided by one programme who disregarded elements of the shadowing requirement, stating:

60 Journal of Practice Teaching \& Learning 7(3) 2006-07, pp.49-69. DOI: 10.1921/19643. (C) w\&b 
'Shadowing' and its place in preparing students for practice learning

The student does not necessarily shadow a qualified social worker. The partnership took this decision at the outset as the local authorities could not deliver this opportunity on top of all assessed placements.

Completing the shadowing experience and finding sufficient practice learning days was highlighted as problematic.

The sample for the questionnaire was drawn from a group of 33 students who undertook a five-day shadowing experience with a qualified and experienced social worker. The placements took place in statutory, voluntary and independent services in three local regions in Southern England. Prior to the placement a preparatory workshop was held to explain the process and expectation and to listen and respond to any queries and anxieties raised about the experience. Separate days were attended by social workers from the agencies providing the experience and by students about to undertake the experience. Both groups identified beginning to learn to integrate theory in practice and questioning but the social workers emphasised increasing student knowledge of the 'realities' of social work practice, and the potential impact on one's personal life whilst students stressed the wish to reduce anxieties about practice learning and social work in general, wanting reassurance and to develop confidence. Students also wanted to develop enthusiasm and to enjoy the experience.

A sample of seven students completed self-efficacy questionnaire examining student confidence in:

- working with people who use social work services

- written tasks

- resilience and dealing with stress (emotional intelligence)

- integrating theory in practice

- working with other professionals

The questionnaire was undertaken prior to the shadowing experience and subsequent to it when students were also asked to complete a retrospective test - asking how confident they thought they were prior to undertaking the experience - to control for any changes in confidence that may have resulted from shadowing. Low numbers completing the questionnaire reduces the power of the analysis, but the results indicate that student mean confidence increased on all subscales and points tested and the retrospective test indicates that perceptions of increases

61 Journal of Practice Teaching \& Learning 7(3) 2006-07, pp.49-69. DOI: 10.1921/19643. (C) wEb 
Table 2

Pre-, post- and retrospective test means, standard deviations and significance

\begin{tabular}{lccccc}
\hline & $\begin{array}{c}\text { pre-test } \\
\text { mean SD }\end{array}$ & $\begin{array}{c}\text { post-test } \\
\text { mean SD }\end{array}$ & t tests & $\begin{array}{c}\text { retrospective test } \\
\text { mean SD }\end{array}$ \\
\hline $\begin{array}{l}\text { Subscale one } \\
\text { working with } \\
\text { people }\end{array}$ & $6.5(0.6)$ & $8.1(0.5)$ & $\begin{array}{l}12.746 \\
(<0.0001 \text { sig. })\end{array}$ & $6.2(0.4)$ \\
$\begin{array}{l}\text { Subscale two } \\
\text { written skills }\end{array}$ & $6.2(0) 2$. & $7.3(0.3)$ & $\begin{array}{l}16 \\
(0.04 \text { sig. })\end{array}$ & \\
& & & & $5.6(0.2)$
\end{tabular}

Subscale three resilience and dealing with stress

$\begin{array}{lllll}5.7(0.9) & 7.3(0.6) & 10.553 & 5.6 & (0.7) \\ & & (<0.0001 \mathrm{sig} .)\end{array}$

subscale four integrating theory and practice

$$
6.5(0.6) \quad 7.9(0.4) \quad \begin{aligned}
& 10.435 \\
&
\end{aligned} \quad(<0.0001 \mathrm{sig} .)
$$

Subscale five

working with $7.1(0.4)$ $8.2(0.4)$

10.752 $6.4(0.3)$ other professionals $(<0.0001 \mathrm{sig}$.

in confidence are higher than when first completed suggesting validity of the findings despite the low response rate (see table 2). T-tests were used to analyse the data. Whilst again acknowledging that representativeness is limited given the low sample size, the increases in confidence reported are highly significant in statistical terms.

A replication of the self efficacy questionnaire the following year demonstrated similar increases in self-efficacy following the shadowing experience, thus adding weight to the findings. When the results of the two groups were combined they showed, again, a high degree of statistical significance.

A short open-ended questionnaire was given to students as a followup when on placement. The questionnaire asked students to reflect on the shadowing experience. Seven students completed the questionnaire,

62 Journal of Practice Teaching \& Learning 7(3) 2006-07, pp.49-69. DOI: 10.1921/19643. @ wEb 
six responding positively stating that the experience helped them to prepare for practice learning and one indicated 'maybe'. The ways in which shadowing was believed to have helped prepare students was in providing a foundation knowledge of service user groups and legislation, giving knowledge of assessment skills, processes and working with others and in linking theory and practice and policies and practice. One student provided a slightly dichotomous view of theory and practice stating that shadowing began to provide a 'reality of why we are studying social work - in order to actually work, rather than study', echoing some of the concerns raised in Walton's (2005) work. Shadowing was also believed to assist learning by providing an opportunity to discuss with other social workers who had been through a qualifying programme, and by increasing students' confidence in working in professionals settings. As one respondent commented:

I was based at a family day centre and saw so much happen in one week: home visits, assessments, multidisciplinary teams/multi-agency reviews.

Learnt the hours that social workers work.

Respondents found the direct contact with people who used services, home visits and team meetings most helpful. They also valued relating theory to practice, observing what happens in practice - assessments, duty, teamwork and so on - and recognising that not everything goes to plan. Interestingly, the latter point gave students confidence, knowing that they would not be expected to 'get things right' all the time. One student commented that it helped 'me gain confidence, especially to do with my age'.

One student stated that more time was needed to prepare for practice learning including more time to shadow social workers. Indeed, the short time allotted to the experience was considered to be the least helpful aspect of the experience - 'too short - just settled in and time to leave', and being in the office observing paperwork, case recording which led to calls for more structured activities and ensuring that there were opportunities for observing and learning throughout the placement.

Not surprisingly, comments relating to possible improvements in the experience included making it longer than five days, increasing the diversity of opportunities and contrasting experiences, having a meeting between social worker and student prior to the experience and ensuring that supervisory social workers were available for the experience after agreeing to it.

63 Journal of Practice Teaching \& Learning 7(3) 2006-07, pp.49-69. DOI: 10.1921/19643. @ wE-b 


\section{Discussion}

This study was limited in respect of its sample size of programmes participating and the number of student respondents to the questionnaire. Furthermore, data concerning student experiences in the second part of the study relate specifically to one programme of social work. The context of difference and 'fuzziness' of criteria set for the shadowing experience, therefore, further limit the potential for generalisation of findings. However, the findings do suggest that five key areas require attention if the possible benefits of the shadowing experience are to be maximised. These are:

- Duration, identifying minimum requirements and standardisation of practice

- The 'fit' and integration with practice learning opportunities

- How the experience is assessed as part of the required curriculum

- Attention to planning and detail

- Resources and funding issues

Variation in the length of shadowing opportunities presents students across England with differential experiences. This may marginalise the role of shadowing in programmes where it is thought the lack of guidance and criteria seem proportionate to its importance. This could be addressed by standardisation of length. Although standardising the duration may present difficulties, especially given contemporary pressures on practice learning opportunities, practice teachers and assessors as well as the agencies providing the experiences, it might be possible to integrate shadowing within the 200 days or introduce broad parameters for completion which may allow local and regional needs, in respect of providing sufficient practice days, to be accommodated. However, if this variation is to be addressed adequately there does need to be some specification of the duration; for instance a minimum number of days at least.

It seems that the lack of clear criteria about the place and importance of shadowing and expectations about how and what should be completed has led to diverse practices across universities and, at times, reluctance to engage fully with the process as part of the qualifying curriculum. This, coupled with competing pressures on programme providers may detract from what could be a successful component of social work

64 Journal of Practice Teaching \& Learning 7(3) 2006-07, pp.49-69. DOI: 10.1921/19643. @ wEb 
education. If it is to work as part of the pedagogical underpinning to the qualifying award there need to be clearly articulated expectations attached to the requirement, which, as a university delivered component of the course, should be assessed or acknowledged as contributing to the programme in some overt way (see Le Riche, 2006, for an example). It is also important to ensure that the experience is well-planned and is served by a clearly developed curriculum that specifies exactly what is required and the processes by which these expectations will be achieved (Shardlow and Doel, 1996). The need for structure and clarity is evident from the university and student responses that indicated some enthusiasm for shadowing in principle but a concern where it was rather amorphous and unplanned. For educators and providers to develop such a structured approach would demand a consideration of the place of the experience within the programme as a whole. It would need to be seen as a valuable and essential learning opportunity and as such be something that attracted credit. Again, this would require a fundamental shift for many in the way in which shadowing is conceptualised and would require adequate resources to underpin it.

It may be that the inchoate nature of the current shadowing requirement and therefore potentially divergent expectations of students, providers and programmes has led to different practices. Some may see the shadowing experience as a way of inculcating students into the 'harsh realities' of practice; perhaps hoping to 'sort the wheat from the chaff'. Others may enthusiastically embrace immersion into the practice role but want a protected experience. Whilst different expectations are not necessarily problematic they may be more likely to become so when there are no clear underpinning expectations set for the process.

The question of funding is also crucial both for universities planning, delivering and assessing work which is over and above the expectations of other programmes of study; and for agencies that are requested to provide shadowing opportunities in addition to increased practice learning but, unlike the latter, without recompense. A core criticism expressed by those universities responding to the survey echoed Furness and Gilligan's (2004) call for adequate funding to support shadowing if it is to achieve its full potential as a learning opportunity. Whilst, it may be unlikely that additional funding streams to support shadowing will be found it may be possible to address the need by reconfiguring practice learning to include the observational experience within the mandatory 200 days as suggested above. If this was to be considered possible, a 
firmer evidence base concerning its effectiveness would be needed. The current research represents only a limited study suggestive of the possible benefits that may accrue from the shadowing opportunity.

Resource questions are wider than funding. The demands for practice teachers and practice teacher time have increased with the qualifying degree and placement numbers have risen with the corresponding growth in student numbers. In this context, servicing the shadowing requirement becomes problematic. Perhaps this provides further evidence for embedding shadowing into the assessed work of the qualifying degree. This could then allow those practitioners taking the mandatory module to enable the learning of others as part of post-qualifying training to supervise and assess students on the shadowing placements. This could provide experience for the practitioner and appropriate experiences for students without creating further competition with practice learning opportunities.

The self-efficacy findings are interesting, despite, as noted above, generalising from them being limited because of the low numbers responding. Student confidence in completing social work practice tasks increased after having undertaken the shadowing placement. Confidence, itself, is associated with greater determination and perseverance to complete tasks successfully and to achieve set goals. Thus, the shadowing opportunity can be extremely important in preparing students for practice learning and in contributing to their professional development. This was confirmed by the importance attached to the experience by those taking part, especially once they have started their assessed period of practice learning. Further research in this area is warranted to identify what aspects of shadowing works in increasing confidence and how the self-efficacy of individual students can be enhanced. A model drawn from a task-centred approach to practice learning may provide benefits (Parker, 2005). Students could discuss self-efficacy scores with their academic tutors to develop individualised learning needs and objectives which could be matched with potential experiences. When undertaking shadowing, performance of the tasks could then form the basis of learning and assessment. Increases in selfefficacy, post-shadowing, would be linked with successful completion of tasks and learning objectives which could again form part of the students' professional development plan to be taken forward into practice learning.

66 Journal of Practice Teaching \& Learning 7(3) 2006-07, pp.49-69. DOI: 10.1921/19643. @ wEb 


\section{Concluding remarks}

The shadowing experience is a requirement of the social work degree in England. At the present time there is differential practice amongst programmes, with a range of competing pressures that may prevent its development. The experience has a potentially valuable input to the education of social workers and a contribution to make to preparation for practice in increasing confidence to complete tasks and in reducing anxieties associated with practice learning. If the experience is to reach its potential, greater clarity and standardisation of expectations and requirements is needed. Also, there needs to be an adequate funding stream to support and acknowledge the importance of shadowing.

\section{References}

Bandura, A. (1977) Self-efficacy: toward a unifying theory of behaviour change. Psychological Review, 84, 2, 191-215

Bandura, A. (1986) Social Foundations of Thought and Action: A social cognitive theory. Englewood Cliffs, NJ, Prentice-Hall

Bandura, A. (1994) Self-efficacy. in V.S. Ramchandran (Ed.) Encyclopaedia of Human Behavior. (Vol. 4) New York: Academic Press

Barlow, C. and Coleman, H. (2003) Suitability for practice guidelines for students: A survey of Canadian social work programmes. Social Work Education, 22, 2, 151-64

Department of Health (2002) Requirements for Social Work Training. London: Department of Health

Douglas, H. and Byrne, M. (2005) Improvement by degrees: Reflections on developing quality in practice learning for the new degree in social work in Northern Ireland. Journal of Practice Teaching in Health and Social Work. 6, 3, 45-61

Furness, S. and Gilligan, P. (2004) Fit for purpose: Issues from practice placements, practice teaching and the assessment of students' practice. Social Work Education. $23,4,465-479$

Gelman, C.R. (2004) Anxiety experienced by foundation-year MSW students entering field placement: Implications for admissions, curriculum and field education. Journal of Social Work Education. 40, 1, 39-54

67 Journal of Practice Teaching \& Learning 7(3) 2006-07, pp.49-69. DOI: 10.1921/19643. @ wEb 
General Social Care Council (2003) GSCC Arrangements for Monitoring Social Work Degree Courses: Information for course providers and external examiners. London: GSCC

Gould, N. (2000) Becoming a learning organization. Social Work Education, 19, 6, 585-596

Holden, G., Meenaghan, T., Anastas, J. and Metrey, G. (2002) Outcomes of social work education: The case for social work self-efficacy. Journal of Social Work Education, 38, 1, 115-33

Horner, N. (2006) What is Social Work? (2nd ed.) Exeter: Learning Matters

Lave, J. and Wenger, E. (1991) Situated Learning: Legitimate peripheral participation. Cambridge: Cambridge University Press

Le Riche, P. (2006) Practicing observation in shadowing: Curriculum innovation and learning outcomes in the BA Social Work. Social Work Education, 25, 8, 771-784

Macaulay, C. 2000. Transfer of learning. in: V. E. Cree \& C. Macaulay, Transfer of Learning in Professional and Vocational Learning. London: Routledge

Maidment, J. (2003) Problems experienced by students on field placement: using research findings to inform curriculum design and content. Australian Social Work, 56 1, 50-60

Moon, J.(1999) Reflection in Learning and Professional Development: Theory and practice. London: Kogan Paul

Pajares, F. (2002) Overview of Social Cognitive Theory and of Self-Efficacy [accessed 14th February 2005, from http://www.emory.edu/EDUCATION/mfp/eff.html]

Parker, J. (2005) Should you encourage students to assess themselves in practice learning? A guided self-efficacy approach to practice learning. Journal of Practice Teaching in Health and Social Work, 6, 3, 8-30

Parker, J. (2006) Developing perceptions of competence during practice learning. British Journal of Social Work. 36, 1017-1036

Parker, J. (forthcoming) Developing practice learning for tomorrow's social workers. Social Work Education

Plath, D. (2003) An experienced based model for practice learning: International perspective from Australia. Journal of Practice Teaching in Health and Social Work, 5, 1, 23-38

QAA (2000) Academic Standards: Social Work. (subject benchmark statement), Gloucester: QAA

Shardlow, S. and Doel, M. (1996) Practice Learning and Teaching. Basingstoke: Macmillan

Thompson, N. (2006) Anti-Discriminatory Practice. (4th ed.) Basingstoke: Palgrave

68 Journal of Practice Teaching \& Learning 7(3) 2006-07, pp.49-69. DOI: 10.1921/19643. (C) w\&b 
TOPSS (2002) National Occupational Standards for social workers. [accessed 22nd January 2007 from http://www.topssengland.net/files/cd/England/Main.htm]

Walton, C. (2005) How well does the preparation for practice delivered at the university prepare the student for their first practice learning opportunity in the Social Work Degree? Journal of Practice Teaching, 6, 3, 62-81

Weade, G and Evertson, C. M. (1991) On what can be learned by observing teaching. Theory into Practice. 30, 1, 37-45. 